\title{
Large Scale Power Generation: Up-Skilling Welsh Industry
}

\author{
Elizabeth Locke ${ }^{1} \&$ Sally Hewlett ${ }^{1}$ \\ ${ }^{1}$ School of Engineering, Cardiff University, Wales, UK \\ Correspondence: Elizabeth Locke, School of Engineering, Gas Turbine Research Centre - GTRC, Heol Cefn \\ Gwrgan, Margam, SA13 2EZ, Wales, UK. Tel: 44-794-054-4556. E-mail: lockee@cardiff.ac.uk
}

Received: April 21, 2014 Accepted: May 19, 2014 Online Published: May 25, 2014

doi:10.5539/eer.v4n1p74

URL: http://dx.doi.org/10.5539/eer.v4n1p74

\begin{abstract}
As the move to a low carbon economy presents new challenges for existing industry, there is increasing consensus on the need to address the green skills agenda in order to ensure that the transition is timely and effective. There is however little empirical evidence of the development and delivery of low carbon training courses, specifically in the area of Large Scale Power Generation (LSPG). This study examined the level and form of existing low carbon combustion training in and around Wales and the demand for such training amongst Welsh industry. This is with a view to developing training courses through the Welsh Energy Sector Training project (WEST). Demand for potential WEST courses was found to be positive; specific interest for course content included: The Nature of Fuels, Utilization of Waste, Energy Conversion Processes, Energy Conversion Technologies, Combustion Science, Improving Combustion Efficiency \& Emissions and Combustion Risks \& Hazards. Critically, geographical factors must be taken into account when assessing the most appropriate form of delivery; e-learning could be a useful tool for maximizing participant numbers. An important implication from the research arose; existing training is generally provided at master's degree level, whilst findings indicate a preference for courses at introductory undergraduate degree level. As such a close collaboration with participants is required if the training developed is truly to be of value to industry in Wales during the transition to a low carbon economy.
\end{abstract}

Keywords: low carbon, training, combustion, skills, Wales

\section{Introduction}

'The transition to a low carbon economy will require sufficient appropriately qualified and skilled people to manufacture, install, operate and maintain the low carbon technologies and approaches.' (Jagger et al., 2013:43).

The move to a low carbon economy will place increasing demands on industry as organisations and their employees face new challenges in terms of skills and knowledge. As Jagger et al. (2013) argue, the skills shortage in terms of manufacturing, installing and operating low carbon technologies could critically delay the low carbon transition and increase its cost and duration. It is further reasoned that more attention should be focused on skills and training issues given how fundamental they are to the transition to a low carbon economy. Indeed consideration must be given to those 'deep green' jobs which are critical to a greater uptake of renewable technology. These jobs are central to the "manufacture, installation, and operation of low carbon technologies such as electricity generation, energy efficiency equipment, vehicles and manufactured products" (Jagger et al., 2013:45).

Higher Education (HE) establishments could play a fundamental role in the low carbon transition through research and development programmes and through the provision of training. This will require a close relationship between academia and industry, the success of which will amongst other things, depend on cooperation and mutual benefits. Fairweather (1988:16) suggests that since the 1980's in which it may be considered the 'decade of industry-university liaison,' the higher education sector and industry have a number of drivers for engagement. These include the commercial motivation for a competitive edge and Government policies aiming to boost economic growth. This reflects a changing perception of Universities and Colleges as 'ivory towers' to one in which academic organisations are 'active participants in society.' Indeed this rhetoric underpins the objectives of the Welsh Energy Sector (WEST) project, which aims to develop the low carbon knowledge base in Wales through the development of industry training. WEST is a project within Cardiff 
University's Low Carbon Research Institute (LCRI) Convergence Energy Programme. The project is funded by the European Regional Development Fund (ERDF) through the Welsh Government (with additional support from Welsh Universities and industry). It is intended that training will be delivered at level 4 and above of the Credit and Qualifications Framework Wales (CQFW) which is equivalent to the first year of an Undergraduate Degree (Hewlett, 2014).

There are 5 key research themes within the LCRI which WEST will develop and pilot training modules through; Large Scale Power Generation (LSPG), Hydrogen, Low Carbon Built Environment (LCBE), Marine and Solar PV. The focus of this research is the LSPG theme for which Cardiff University's Gas Turbine Research Centre (GTRC) in Port Talbot, South Wales is responsible. Two members of the team currently lecture on the Sustainable Energy and the Environment MSc, delivered by the School of Engineering and will play central roles in the delivery of training. The training will be offered as fully funded to those individuals who live or work in the Convergence Zone in Wales, illustrated in Figure 1 as the shaded areas. The Convergence Energy Programme aims to enable Welsh industry to lead the way through research and development, supporting job creation, reducing carbon emissions and improving the quality of life in Wales. Central to this is meeting industry needs and developing economic and social benefits through energy sector training.

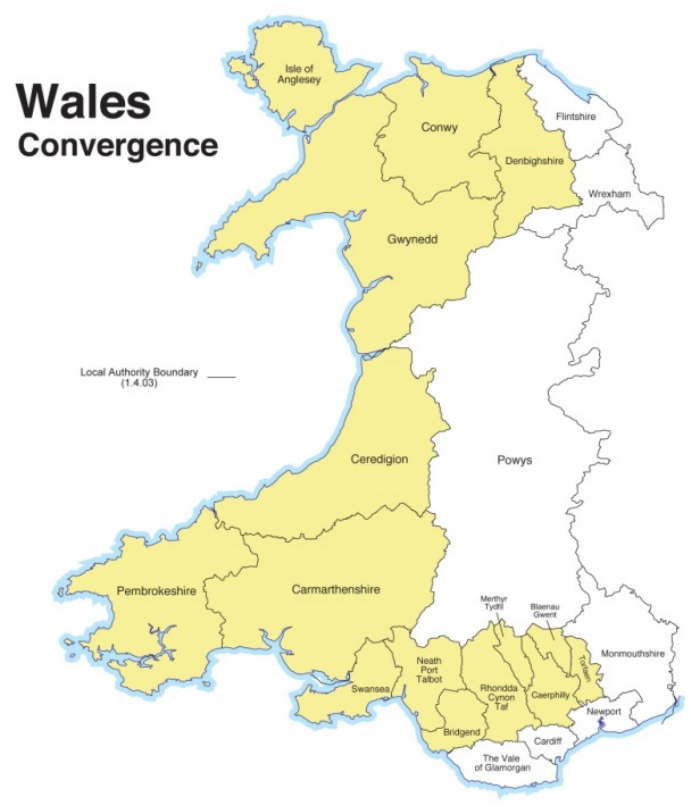

Figure 1. Welsh Convergence Zone

Energy Policy in Wales emphasises the important changes required in the power generation sector:

“...any new fossil fuel plants should be carbon capture ready with fully developed plans for carbon capture and storage; and that these plants maximise efficiency through use of waste heat and co-firing where appropriate" (Wales Gov, 2010:16).

At present gas is the primary fuel source for electricity generation in Wales (approximately $50 \%$ of all electricity generation), coal and nuclear power have declined, with around a $1 / 5$ of electricity generation from low carbon sources (Wales Gov, 2012). Growth in renewable generation, from $2.9 \%$ in 2004 to $5.1 \%$ in 2010, has to some extent negated the fall in electricity generated from nuclear over the same period (Wales Gov, 2012). The total electricity generation in Wales has fallen $10 \%$ over the period, primarily due to a decline in coal and nuclear generating plants (Wales Gov, 2012). Considering the UK as a whole Wales was responsible for $9 \%$ of electricity generation between 2004 and 2010. Policy indicates that, whilst Carbon Capture Storage (CCS) technology is being developed, the priority for Wales lies with improvements in combustion efficiency. This will be achieved through the utilization of waste heat and the firing of renewable and alternative fuels (in combination with fossil fuels). In the longer term, as a result of the long history of coal mining in Wales, deep coal seams are seen as one possible option for storage in CCS, although the viability of this approach is yet to be confirmed. 
Wales' anaerobic digestion capacity, for the production of biogas for combustion, is set to expand to increase energy from waste (EfW) activities; the $£ 5 \mathrm{~m}$ per year sustainable land management scheme 'Glastir' offers a capital grant scheme with the aim of improving business and resource efficiency, and lowering the carbon equivalent emissions of agricultural and horticultural holdings (Wales Gov, 2010). Proposals have also been submitted for an energy from waste (EfW) combined heat and power (CHP) facility in Cardiff with the possibility of a District Heating (DH) network to serve homes and businesses with low carbon heat. According to Viridor Ltd (2013) there is the potential to generate around 30MW of electricity and offer DH for utilisation of low grade heat (Viridor Ltd, 2013). Cardiff City Council will now be examining the feasibility of developing a DH network in the city. Indeed DH has been viewed as a vital low carbon infrastructure by neighbouring Local Authorities, Bridgend, the City and County of Swansea and Neath and Port Talbot Council who have all undertaken feasibility studies for DH in the last three years. Developments in EfW technology specifically concerning emissions control, mean that modern plants are a far different technology from the 'incinerators' of the past, the legacy however can be difficult to dispel. If any further plant developments are to be approved scheme developers will need to work hard to win public and political support through education and consultation (Hewlett, 2014).

Welsh Energy Policy emphasises that low carbon solutions should be locally sustainable, further stressing the important role of industry and organisations:

“....business and industry in particular will play a key role in driving the transition to a low carbon economy" (Wales Gov, 2012:6).

In order to increase the proportion of renewable energy in the production mix, a greater level of awareness and understanding on the use of alternative fuels for power generation is required. The GTRC is undertaking research into the functionality of new combustion systems, components and fuels, under different temperature and operating conditions and pressures. The drive to utilise greater levels of alternative fuels as well as the cleaner combustion of existing fuels (for land based power generation [and aviation sectors]) underpin the research at the GTRC. This reflects the wider need described by Welsh Energy Policy to develop the skills required to build a "competitive Welsh energy supply-chain that can help unlock our own energy resources..." (Wales Gov, 2012:7). To realise this full potential, significant training and up-skilling will be required in order to provide the existing and future workforce with the skills necessary to sustain a competitive low carbon economy. Wales Gov (2012) emphasise that Wales is well placed for the transition to a low carbon economy given the considerable human resources capacity in the low carbon sector in Wales, as well as the natural domestic resources. REA (2012) also highlights green industry in Wales as providing a key example of the job potential in the new green economy; it does however suggest that skills shortages could prevent the UK reaching its renewable potential. In order for Wales to meet the challenges and opportunities that a low carbon economy presents, effort must be focused on developing a strong skills and knowledge base. Effective engagement with industry will be pivotal in tackling the green skills agenda.

The objective of this study is therefore to assess the level of industry interest in LSPG low carbon training in Wales, developed and delivered by the GTRC through the WEST project. In order to achieve this aim it was considered appropriate to employ a survey approach. Firstly investigating the level and form of existing training provision in and around Wales and hence any gaps in training provision, prior to targeting potential course participants to gauge their level of interest in combustion training. As Helm (2007:317) discussing the 'carbon lock-in' of the existing fossil-fuel based energy system, states "the limits of technological change lie not with science and technology, which tend to evolve much faster than governing institutions but rather with the organisational, social and institutional changes that allow the diffusion of new technological solutions." As such significant change is required across these interrelated aspects of sociotechnical complexity. This paper will focus on one such aspect, the organisational change required, focusing on training and skills. The need to address potential skills shortages is widely acknowledged, there is however scant empirical evidence on the potential form and content of low carbon training specifically in the area of large scale power generation (LSPG). The paper is organised as follows: the methodology section provides detail on the main methods employed in the study. The results are then presented and discussed in relation to the low carbon agenda. The paper concludes with recommendations on the importance of a adopting a collaborative approach to ensure that industry training developed is both desired and effective. 


\section{Method}

\subsection{Investigating Existing Course Provision}

Given the LSPG theme focus on alternative fuels and efficiencies in combustion with a special emphasis on gas turbine technology (GT), a review of relevant HE courses available inside and outside Wales was conducted. Of the courses outside Wales, only those institutions considered within practical travelling distance were considered for full-time (FT) and part-time (PT) courses, while institutions further afield were considered where delivery was conducted online (i.e. distance learning). Relevant projects were deemed to be those whereby $H E$ institutions in Wales were offering training direct to industry in relation to the large scale power generation theme. It was also deemed valuable to establish the HE institutions delivering LSPG relevant training to traditional full time HE students from within or near to Wales. In addition training delivered by HE institutions and others outside Wales on the topic of Gas Turbine technology will also be examined.

It was considered important to assign a measure of relevance to the courses found to indicate a degree of overlap. The most useful and concise way to do this was deemed to be the Likert scale as employed by Hall and Allan (2014); as such a 1-5 score was assigned, with 1 illustrating a minor relevance to the topic and 5 showing significant overlap with course material. The benefits of using the Likert scale were considered to be its simplicity of construction, the ease with which participants can read and complete the scoring system and the likelihood of producing a highly reliable scale (Bertram, 2007). However the weaknesses of the approach have also been considered namely, the 'central tendency bias' with participants avoiding extremes of opinion in addition to 'acquiescence bias' in which participants may seek to 'agree' with the researcher, providing answers that are assumed to be desirable by the researcher (Bertram, 2007:8). In addition issues of reproducibility and validity have been considered.

\subsection{Assessing Industry Appetite}

In order to assess the level of demand for low carbon training within Welsh industry an existing database created by Cardiff University's Engineering School was utilised. The database consists of around 1000 organisations, from which a review process enabled the companies to be refined to 60 relevant target participants (i.e. those assumed to be using large scale power generation technology), located within the Convergence Zone. In addition efforts were made to locate the contact details of all power stations in Wales. The power stations were considered a primary target as the principal users of industrial gas turbines in Wales. As such they were viewed as a vital source of potential participants and whose opinion was critical in the design and development of a relevant GT educational program.

This enabled the database to grow to 75 companies who could potentially be interested in attending LSPG WEST training. The companies were targeted with a questionnaire sent to the Training Officer; this was deemed sensible given the nature of the project. In addition an event was delivered, the 'LCRI LSPG Seminar and Exposition,' in which low carbon power generation energy companies were invited to hear more about the training courses to be developed by the LSPG theme. As part of the event a workshop was held describing to attendees the nature and purpose of the WEST project. The presentation also proposed possible course topics and structure and attendees were invited to complete a questionnaire to register their interest in the different proposals. Two companies in attendance completed the questionnaire, bringing the total questionnaire responses to 9 companies. The questionnaire was also made available on the GTRC and WEST specific website, however no participants responded through this channel.

Descriptions of potential core topics within the theme of LSPG were devised and respondents were asked to rate their preference for the subjects as well as the preferred level of training. A Likert Scale was also utilized for the assessment of industry appetite employing a 1-4 rating for the level of interest in proposed topics (i.e. 1: of no interest, 2: of minor interest, 3: fairly interested, 4: definitely interested). For ease of comparison and in order to generate a holistic assessment of demand in light of the research objectives, data analysis consisted of generating scores for each topic based on total participant responses in a summative fashion. This enabled cross-topic comparison, allowing as it does for the weighting of respective topics. Data was displayed in the form of a bar chart, which was considered a clear and visually appealing way to illustrate survey findings.

\section{Results}

The following section provides an overview of the main empirical findings; firstly the investigation of LSPG related courses delivered in and around Wales (through the survey of Sector Skills Councils and HE establishments) prior to the results of the industry survey. 


\subsection{Existing Training Provision}

\subsubsection{Sector Skills Councils}

Of the large number of sector skills councils considered, only a selection were deemed to be most relevant to LSPG related training. These included The Sector Skills Council for Science, Engineering and Manufacturing (SEMTA) and the Construction Industry Training Board (CITB). Sector Skills Councils were considered the most significant agents for sourcing training for industry. However upon investigating the training offered, predominantly through the websites of each respective Council, the relevance to LSPG related training was found to be minimal. Sector Skills Councils are engaged with their industries to train predominantly at level 3 of the CQFW and below, focusing on practical skills and mandatory qualifications. As such the potential for duplication with WEST training materials was deemed to be low.

Table 1. Wales \& surrounding areas LSPG related HE course provision

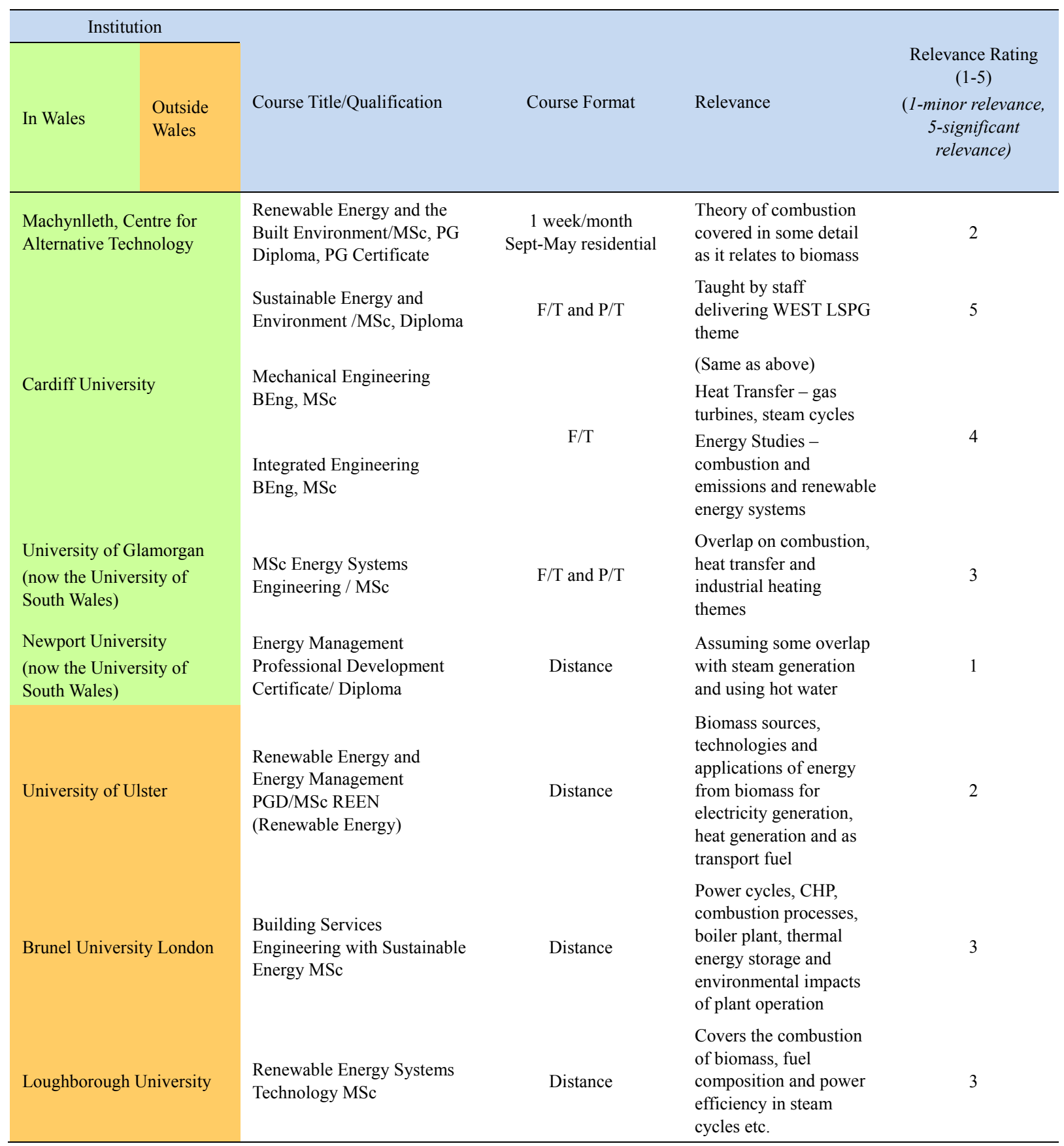

Note. $\mathrm{FT}=$ Full-Time, $\mathrm{PT}=$ Part-Time. 


\subsubsection{Higher Education Institutions Within and Close to Wales}

Given the LSPG focus on alternative fuels and efficiencies in combustion, with a special emphasis on gas turbine technology, a review of relevant HE courses available inside and outside Wales was conducted. It was found that none of the HE institutions in Wales are presently offering combustion related training courses directly to industry. Therefore, any combustion training offered by LSPG should not overlap with any other similar initiatives in Wales. In addition it was deemed valuable to ascertain the level of existing training provision delivered by HE institutions to traditional full time HE students in and around Wales.

In total, 42 different courses across 21 institutions were reviewed. Information regarding course content was gathered in a variety of ways. The content of courses being delivered within Cardiff School of Engineering was obtained directly through the 'School Office' itself. For other courses module descriptions could be found on websites in most instances, although many descriptions were too vague to be of practical use. In these cases the institutions were contacted directly to request further clarification. Only two institutions failed to respond about their respective courses ( 1 course each) but overlap was considered unlikely or minimal at best, so these courses have not been considered relevant.

As illustrated in Table 1, it was found that 9 courses currently being delivered in Wales possessed some relevant material, of these 6 were offered by Welsh institutions, with 5 delivered either within Cardiff University or within 15 miles of Cardiff City Centre. The University of South Wales (formerly known as Newport University) was the only Welsh Institution offering distance learning, however the relevance to LSPG was found to be minimal. Should anyone wish to pursue training in the field of LSPG, they may have to travel a considerable distance for traditional face-to-face training delivery. One could deduce that distance learning could be an important way to increase the numbers of employees willing and able to undergo training due to its convenience. It could also deliver the flexibility required for individuals anywhere in Wales who wish to pursue training and for whom full or part time study is not a realistic option without significant changes in their employment arrangements. Consideration will now be given to gas turbine specific courses.

\subsubsection{Gas Turbine Specific Courses}

There are gas turbine specific courses being delivered in many countries, but for relevance to the population of Wales only the courses delivered in English have been investigated (there are no courses delivered in Welsh).

Cranfield University is the primary provider of gas turbine related short courses in the UK, with approximately 20 gas turbine engineering continuing professional development (CPD) short courses advertised. During 2013, four training courses were offered: Combined Cycle Gas Turbines, Design and Performance of the Axial Turbine Component of Gas Turbine Engines, Gas Turbine Combustion and Gas Turbine Technology for Operations and Maintenance Engineers.

As an example, the Gas Turbine Combustion course covers the following topics:

a. Pre combustor diffusers - its role, design etc.

b. Combustion in the gas turbine - performance and design criteria, aerodynamics, fuel injection methods, retrofitting for multi-fuel capability, ignition flame stabilisation

c. Pollutants - carbon formation and gaseous pollutants

d. Fuels - variability and alternative fuels substitution

e. Computational modelling

f. Heat transfer

The course is primarily aimed at people actively engaged in the gas turbine industry or those about to enter the field with a degree in Science or Engineering (or equivalent).

The University of Leeds offers also CPD courses on combustion and gas turbine technology. Outside of the UK, the University of California, Irvine Combustion Laboratory offers a specific gas turbine course primarily for people already engaged in the research, design and development of gas turbine combustion. The course content is outlined below:

a. Fundamentals of combustion - flame temperature, speed and classification, flammability limits, stoichiometry, chemical dissociation and kinetics and evaporation of liquid sprays etc.

b. Gas turbine combustion - basic design features and types of chambers, performance criteria (e.g. emissions), performance and pressure loss, diffuser design, fuel preparation, ignition and more. 
c. Low emissions gas turbine combustion - carbon formation, fuel properties, gaseous pollutants, low NOx design and regulation.

d. Experimental methods - model combustors, diagnostic tools, spray characterisation, high temperature and pressure experiments and computational analysis.

The syllabus of this course is very similar to the course delivered by Cranfield University, which suggests a possible core formula for the design of a gas turbine specific course for potential WEST training.

\subsection{Establishing Industry Demand}

Table 2 provides an overview of the nature of the organizations who responded.

Table 2. Industry respondents

\begin{tabular}{l}
\hline Description \\
\hline Power station \\
Gas/diesel engine provider \\
Energy consultancy \\
Biomass heating organisation \\
Power station \\
Forestry \& timber company \\
A non-profit company operating an internet based \\
network to support its members in the implementation \\
of biopower technology fuels \\
Chemical manufacturer \\
Tissue manufacturer
\end{tabular}

It was deemed important to ascertain the level of interest in the proposed course topics across a range of educational levels (from undergraduate to industry professional/academic). The respondents were asked to rank their level of interest in each of the 13 proposed course topics on a scale of 1-4 (i.e. 1: of no interest, 2: of minor interest, 3: fairly interested, 4: definitely interested).

The topics 1-13 can be summarised as follows:

At undergraduate level:

a. Topic 1- The Nature of Fuels

b. Topic 2- Utilisation of Waste

c. Topic 3- Energy Conversion Processes - (i.e. combustion, gasification and pyrolysis)

d. Topic 4- Energy Conversion Technologies

e. Topic 5-Combustion Science

f. Topic 6- Improving Combustion Efficiency and Emissions

g. Topic 7-Combustion Risks and Hazards

h. Topic 8- A Bespoke Course concerning a company's specific energy conversion technologies and processes, developed in collaboration with the company

At graduate level:

i. Topic 9- Gas Turbine Emissions

j. Topic 10- Gas Turbine Flame Stability and Combustion Noise

k. Topic 11- Gas Turbines: Fuel Variability and Alternative Fuels

1. Topic 12-Combustion Performance in Gas Turbines and Thermodynamic Cycles

For industry professionals and academics:

m. Topic 13- Gas Turbine Theory, Design and Performance Course 
Figure 2 displays the results from the questionnaire. The topic scores given by the respondents were added to give a total score for each topic (shown in brackets under the topic number). Each company's scores for individual topics are displayed in Figure 2. For example, for topic 1 the Tissue Manufacturer awarded a score of 4, whilst the Chemical Manufacturer assigned a score of 2.

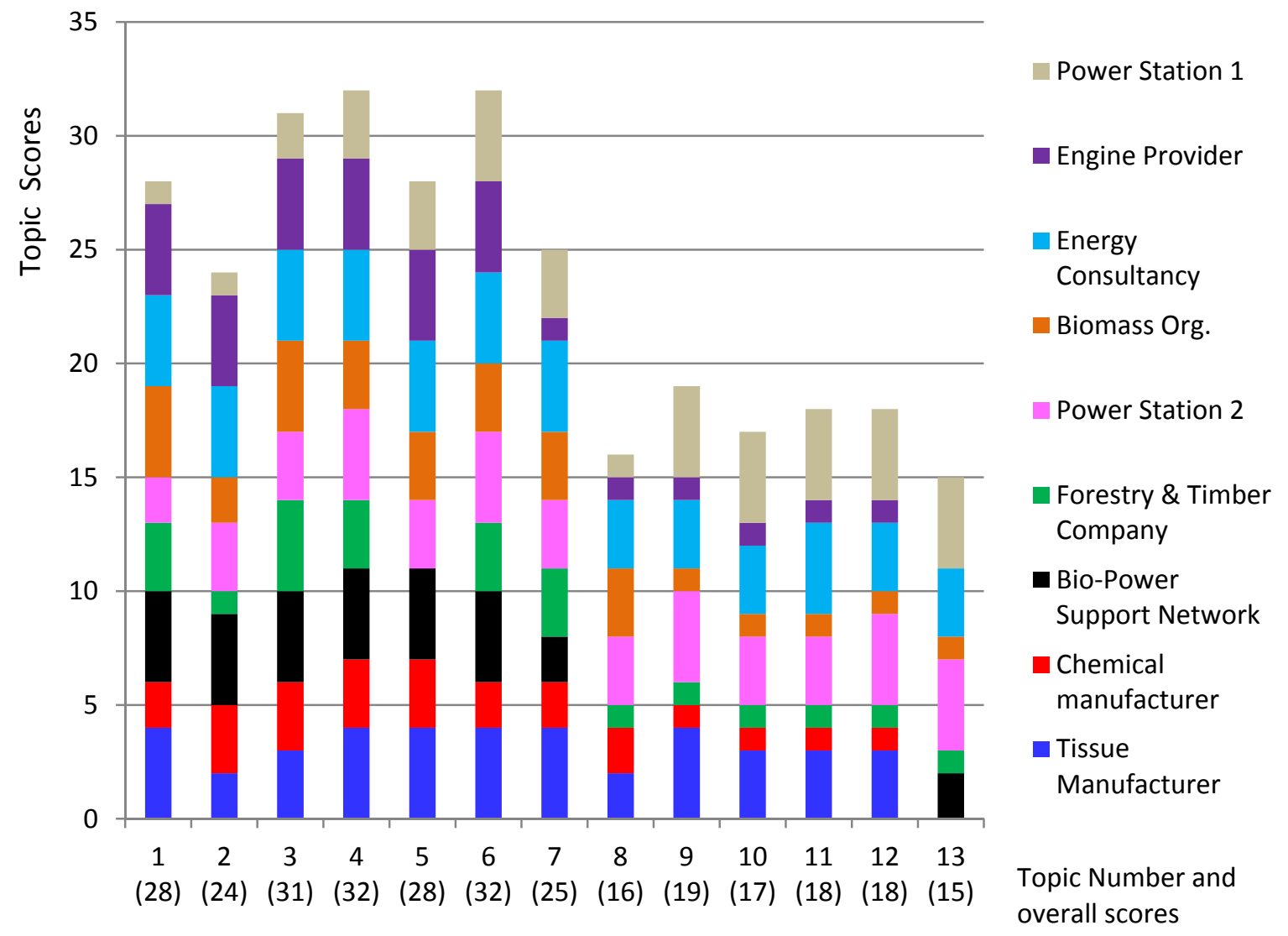

Figure 2. Proposed course topics feedback scores

As can be seen, topics 1-7 scored higher than the remaining topics. These topics are less specialised than topics 8-13 and so demonstrate an industry appetite for training at a fundamental, introductory level. It is not surprising that of the four companies showing a real interest in the more specialised gas turbine courses (i.e. scoring topics at 3 or more), two manage power stations. Those companies scoring the more specialised courses highly also scored the fundamental, introductory level courses highly, indicating the need for staff training at all levels within these companies. Training can be offered by LSPG at all educational levels however feedback indicates a more widespread demand for introductory level courses.

\section{Discussion \& Conclusion}

\subsection{Positive Industry Response}

The importance of matching industry demand for training with teaching and research expertise is appreciated by Yadav (2012). Indeed training developed should marry up academic staff expertise, industry's established topics of interest and low carbon policy in the field of power, heat generation and utilisation. The survey of industry demand indicates a positive response to LSPG related training at an introductory level, which is well matched with the skills base of the GTRC. Indeed there is the potential to train the manufacturing and power generation sectors on a variety of combustion topics related to lowering carbon emissions in heat and power generation.

It is important to appreciate the dynamic nature of industry which means that needs evolve and hence training should be updated periodically to ensure the relevance of course materials (Yadav, 2012). The results could be strengthened with further industry surveying in order to increase the generalizability of findings, although 'questionnaire fatigue' presents a challenge to the survey approach. Efforts to engage with prospective survey 
targets directly in face-to-face meetings or further workshops could increase the response rate and develop a richer feeling for industry demand, although this would be a more time-consuming option.

Findings suggest that the lack of LSPG related training currently offered by Welsh institutions directly to industry means that training developed within WEST should not overlap with any existing projects and hence WEST training can be considered as meeting a genuine need within industry. The courses created should be delivered at a level which is accessible to individuals in a variety of workplace roles; efficient operation of a facility is an objective of workers involved in maintenance, operation and management. Indeed an understanding of efficient combustion processes, alternative fuels and new technologies is the key to lowering carbon emissions now and in the future, so training materials must be developed with the educational background of the potential audience in mind. However the WEST project stipulates training at level 4 and above of the CQFW, as such a balance must be achieved between delivering the desired level of training and ensuring that participants are able to achieve the learning outcomes. As Arslan and Kuş (2012) note, it is difficult to prepare training content for participants who may have varying levels of capabilities in terms of knowledge and skills.

Courses could be aimed at Wales' current workforce in the form of CPD training - to promote retention of skills and to build relationships between the University and industry participants. The importance of CPD training to engineers is well documented in Williamson et al. (2001), who state that the breadth of knowledge required by engineers and the rapid pace of technological change mean that CPD's are an imperative learning tool for the engineering industry. In addition the delivery format should be flexible enough to allow training to fit around a working life. Short courses or day release from work to attend the University or GTRC would be an option for individuals living close to the facilities. Distance learning (e.g. e-learning) would most likely be the preferred option for those individuals living further afield, as was stated in one of the questionnaire responses from a company based in Powys, North Wales. A combination of both e-learning and attendance for those in South Wales would also help to minimise time spent away from the workplace.

\subsection{Creating Value for Welsh Industry}

There is a very little empirical evidence on the demand for, development and delivery of low carbon training, specifically in the area of LSPG. This study could provide value for organisational bodies seeking to provide low carbon skills training. The findings suggest that industry in Wales is receptive to WEST LSPG training courses; initial consultation on the prospect of WEST LSPG educational courses has been wholly encouraging. The training to be developed fits well with Welsh Energy Policy, as such policy objectives and industry's perceived training needs can be considered as aligned. LSPG low carbon combustion courses can help deliver the knowledge necessary for the improved energy conversion efficiencies in the short term and can also introduce the workforce to the potential of alternative fuels. The courses could help to lay the groundwork for greater acceptance of future low carbon technological developments such as CCS.

The research has indicated the importance of geographical considerations in respect of the most effective mode of training. At present existing training provision in terms of HE establishments in Wales delivering direct to industry is limited, the training offered to full time HE students by establishments in and around Wales shows some relevance to LSPG, although not to a degree to which overlap or duplication may be an issue. Given the current concentration of existing training options in and around Cardiff City Centre, it would seem that distance learning, potentially in an e-learning format could be a valuable way to capture those participants who are unable to travel large distances (or who cannot spare the time to enrol as a part or full-time student) to attend traditional face-to-face training delivery. Considering a blended learning option with some element of e-learning along with traditional face-to-face delivery, the location of the GTRC in Port Talbot, South Wales, situated between the city of Swansea and the large town of Bridgend could also help to mitigate the travelling inconvenience for individuals in South Wales, should courses be delivered at the facility. In addition the criticality of delivering training at the appropriate level must be appreciated, current training is generally provided at masters degree level (level 5 of the CQFW) whilst industry is seeking training at a lower introductory level. This suggests that efforts to improve national green skills must be undertaken in collaboration with industry to ensure a coherent and appropriate approach. It must also be recognised that Energy Policy is vulnerable to economics as such a pragmatic approach to the development of training materials should be adopted (Hewlett, 2014). As RAE (2010:5) states, "The future direction and success of the UK economy is largely predicated on the availability of the right skills." It is further argued that, "the right skills is a matter of strategic national importance and, as such, transcend party politics" (2010:5). The need for a coordinated approach to Energy Policy and education is therefore vital in order to ensure that industry is confident in the direction of the market and likewise skills providers can develop relevant training. The formation of an Industrial Advisory Group (IAG) could be an 
important source of industry insight employing a collaborative approach to course development, ensuring that training delivered will truly be of value to Welsh industry in the transition to a low carbon economy.

\section{Acknowledgments}

The authors would like to thank Steve Morris and Dr Yura Sevcenco at the GTRC for their advice and guidance and Dr Dean Stroud, Dr Samantha Yandle, \& Professor Andrew Thomas for their comments on earlier drafts.

\section{References}

Acworth, E. B. (2008). University-industry engagement: The formation of the Knowledge Integration Community (KIC) model at the Cambridge-MIT Institute. Research Policy, 1241-1254. http://dx.doi.org/10.1016/j.respol.2008.04.022

Alan, B., \& Bell, E. (2011). Business Research Methods. Oxford: Oxford University Press.

Arlett, C., Lamb, F., Dales, R., Willis, L., \& Hurdle, E.(2010). Engineering Education. Journal of the Higher Education Academy Engineering Subject Centre, 5(2), 18-25.

Arsland, R., Kus, A., (2012). A Modular Approach for Training Employees in the Automotive Service Sector. Industry \& Higher Education, 26(5), 403-408. http://dx.doi.org/10.5367/ihe.2012.0116

Bertram, D., (2007). Likert Scales.. are the Meaning of Life....Canada. University of Calgary.

Bruneel, J., D'Esteb, P., \& Salter, A. (2010). Investigating the factors that diminish the barriers to university-industry collaboration. Research Policy, 858-868. http://dx.doi.org/10.1016/j.respol.2010.03.006

Collis, \& Hussey. (2009). Business Research: A Practical Guide for Undergraduate \& Postgraduate Students (3rd ed.). Palgrae Macmillan.

Committee on Climate Change. (2013). Reducing the UK's Carbon Footprint and Managing Competitiveness Risks. United Kingdom: Committee on Climate Change.

Dasgupta, P., \& David, P. (1994) in Bruneel, J., D'Esteb, P., \& Saltera, A. (2010). Investigating the factors that diminish the barriers to university-industry collaboration. Research Policy, 858-868.

DECC. (2013). UKCS Oil and Gas Production Projections.

Edmondson, G., Valigra, L., Kenward, M., Hudson, R. L., \& Belfield, H. (2012). Making Industry-University Partnerships Work: Lessons from Successful Collaborations. Science Business Innovation Board.

Fairweather, J. (1988). Entrepreneurship and Higher Education: Lessons for Colleges, Universities \& Industry. Washington: ASHE-ERIC Higher Education Report No.6.

Gov. (2013). The Ue of Low Carbon Technologies. Retrieved 2013, from https://www.gov.uk/government/policies/increasing-the-use-of-low-carbon-technologies/supporting-pages/h eat-networks

Hall, C., \& Allan, F. (2014). Influencing Carbon Behaviours: What Pscyhological and Demographic Factors Contribute to Individual Differences in Home Energy Use Reduction and Transportation Mode Decisions. Energy and Environment Research, 1-14.

Helm, D. (2007). The New Energy Paradigm. Oxford: The Oxford University Press.

Hemingway, J., \& Michaels, C. (2012). Special feature - sub national electricity figures, Electricity generation and supply figures for Scotland, Wales, Northern Ireland and England, 2008 to 2011. December 2012. DECC. Retrieved from https://www.gov.uk/government/uploads/system/uploads/attachment_data/file/ 65841/7345-elec-gen-2008-2011-et-article.pdf

Hewlett, S. (2014). Sector Skills Training Needs Analysis. LCRI. WEST

Jagger, N., Foxon, T., \& Andy, G. (2013). Skills Constrains and the Low Carbon Transition. Climate Policy, 13(1), 43-47. http://dx.doi.org/10.1080/14693062.2012.709079

Kitson, M., \& Hughes, A. (2009). University-Industry Knowledge Exchange: Demand Pull, Supply Push and the Public Space Role of Higher Education Institiuion: Full Research Report, ESRC End of Award Report, RES-171-25-0018. Swindon: ESRC.

Mead, N. A., Kathy, B., Jimmy, L., O'Mary, G., \& Parish, C. (1999). Industry/university collaborations: different perspectives heighten mutual opportunities. The Journal of Systems and Software, 49, 155-162. http://dx.doi.org/10.1016/S0164-1212(99)00091-6 
RAE. (2010). Educating Engineers for the 21st Century. The Royal Academy of Engineering

REA. (2012). Renewable Energy: Made in Britain. Renewable Energy Association.

Rosenberg, N. (1982). Inside the Black Box: Technology \& Economics. Cambridge: Cambridge University Press.

Salter, A., Tartari, V., D'Este, P., \& Neely, A. (2010). Exploring UK Academic Attitudes to Collaborating with Industry and Entrepeneurship. UK Innovation Research Council.

Stroud, D., \& Fairbrother, P. (2008). The importance of workplace learning for trade unions: a study of the steel industry. Studies in Continuing Education, 30(3), 231-245. http://dx.doi.org/10.1080/01580370802439920

Vaidya, A., \& Charkha, S. (2008). Barriers \& Motivational aspects of University-Industry Linkage. CURIE Journal, 1(3), 58-63.

Viridor Ltd. (2013). Transforming Waste - Cardiff EfW. Retrieved April 23, 2013, from $\mathrm{http} / / / \mathrm{www}$. viridor.co.uk/our-developments/cardiff-efw

Wales Gov. (2010). A Low Carbon Revolution. Welsh Government.

Wales Gov. (2012). Energy Wales: A Low Carbon Transition. Welsh Government.

Williamson, S., Lamb, F., \& Davis, L. (2001). Education Issues are the Same Across the World. International Conference on Engineering Education. Aug 6-10. Norway.

Yadav, D. (2012). University Aviation Degree Courses: A Study of Labour Market and Student Retention Challenges for Sustainable Course Development. Industry \& Higher Education, 26(5), 393-401. http://dx.doi.org/10.5367/ihe.2012.0118

\section{Copyrights}

Copyright for this article is retained by the author(s), with first publication rights granted to the journal.

This is an open-access article distributed under the terms and conditions of the Creative Commons Attribution license (http://creativecommons.org/licenses/by/3.0/). 